\title{
MODALIZAÇÕES EM ARTIGOS DE OPINIÃO COMO REDAÇÃO DE VESTIBULAR
}

\author{
(Modalizations in opinion article as an essay from entrance examination) \\ (Modalizaciones en artículos de opinión como ensayo de admisión del examen de ingreso a la \\ universidad)
}

\author{
Gabriela Pepis Belinelli ${ }^{1}$ \\ Eliana Merlin Deganutti de Barros ${ }^{2}$ \\ Marilúcia dos Santos Domingos Striquer ${ }^{3}$ \\ Universidade Estadual do Norte do Paraná (UENP)
}

\begin{abstract}
RESUMO
O foco deste trabalho é o desenvolvimento de uma pesquisa de natureza qualitativa, de cunho documental, tendo como objeto principal as redações dos candidatos do vestibular da Universidade Estadual do Norte do Paraná (UENP) do ano de 2018. A investigação centra-se na análise dos recursos modalizadores mobilizados pelos candidatos para a produção de textos do gênero "artigo de opinião como redação de vestibular", tendo como aporte teórico os estudos desenvolvidos por Bronckart (2003), no interior do Interacionismo Sociodiscursivo (ISD), sobre modalização, um dos elementos dos mecanismos enunciativos do texto. O objetivo da pesquisa é analisar como são articuladas as modalizações no processo de argumentação da escrita do artigo de opinião como redação de vestibular, bem como a influência do ato de modalizar o discurso na construção desse gênero. Os resultados apontam uma incidência grande de modalizadores lógicos e deônticos, a inexpressividade de modalizadores apreciativos e a inexistência de modalizadores pragmáticos.
\end{abstract}

Palavras-chave: Interacionismo Sociodiscursivo. Produção escrita. Gênero textual. Ensino.

\begin{abstract}
The focus of this work is the development of a qualitative research, with documentary nature, having as main object the essays of applicants of the college entrance exam from State University of Northern Parana (UENP) in 2018. The investigation is centered on the analysis of the modalizers resources mobilized by the applicants to produce texts from the genre "opinion article as an essay from entrance examination", having as theoretical basis the studies developed by Bronckart (2003), inside the Sociodiscursive Interactionism (ISD), about modalizations, one of the enunciative mechanisms of the text. The aim of the research is analyse how modalizations are articulated in the argumentation process of writing an opinion article as an essay of entrance exam, as well as the influence of modalizing the discourse in the construction of this genre. The results indicate a high incidence of logical and deontic modalizers, the lack of appreciative modalizers and the absence of pragmatic modalizers.
\end{abstract}

Keywords: Opinion Article. Sociodiscursive Interactionism. Enunciative Mechanisms. Modalizations.

\footnotetext{
1 Mestranda do Programa de Pós-Graduação Mestrado Profissional em Ensino da Universidade Estadual do Norte do Paraná (UENP). Graduada em Letras - Português/Inglês pela Universidade Estadual do Norte do Paraná (UENP). Membro do Grupo de Pesquisa Diálogos Linguísticos e Ensino (DIALE/CNPq). gabriela_pepis@outlook.com.

${ }^{2}$ Doutora em Estudos da Linguagem. Professora adjunta da Universidade Estadual do Norte do Paraná (UENP). Atua na Graduação em Letras, no Mestrado Profissional em Letras em Rede (PROFLETRAS) e no Mestrado Profissional em Ensino (PPGEN) da UENP. Líder do GP DIALE (CNPq). elianamerlin@uenp.edu.br.

${ }^{3}$ Doutora em Estudos da Linguagem. Professora adjunta da Universidade Estadual do Norte do Paraná (UENP). Atua na Graduação em Letras, no PROFLETRAS e no PPGEN da UENP. Pesquisadora do GP DIALE (CNPq). marilucia@uenp.edu.br.
} 


\section{RESUMEN}

El objetivo de este trabajo es el desarrollo de una investigación cualitativa, de naturaleza documental, que tiene como objeto principal los ensayos de admisión de los candidatos del examen de ingreso a la Universidad Estatal del Norte de Paraná (UENP) del año de 2018. Lo enfoque de investigación es el análisis de los recursos de modalización movilizados por los candidatos para la producción de textos del género "artículo de opinión como ensayo de admisión del examen de ingreso a la universidad", tomando como soporte teórico los estudios hechos por Bronckart (2003), dentro del Interaccionismo Sociodiscursivo (ISD), sobre la modalización, uno de los elementos de los mecanismos enunciativos del texto. El objetivo de la investigación es analizar cómo los tipos de modalización se articulan en el proceso de argumentación de la redacción del artículo de opinión como ensayo de admisión del examen de ingreso a la universidad y, de igual forma, la influencia del acto de modalizar el discurso en la construcción del género en foco. Los resultados indican una alta incidencia de modalizaciones lógicas y deónticas, la inexpresividad de modalización apreciativa y la ausencia de modalización pragmática.

Palabras Clave: Artículo de opinión. Interaccionismo Sociodiscursivo. Mecanismos enunciativos. Modalizaciones.

Recebido em: abril 2020

Aceito em: maio 2020

DOI: $10.26512 /$ les.v21i1.31033

\section{Introdução}

Muitos pesquisadores que investigam o ensino e a aprendizagem da língua portuguesa na Educação Básica têm observado o efeito retroativo que as provas de redação dos vestibulares desempenham no (re)direcionamento do ensino, sobretudo, no Ensino Médio. Isso tem impulsionado diversos estudiosos da linguagem a investigarem a produção de textos no contexto de seleção de vestibular e sua relação com o ensino da escrita na Educação Básica que, tradicionalmente, orientava-se (ou orienta-se) pela perspectiva estrutural dos textos escolares, ancorados, quase sempre, nas tradicionais tipologias textuais: narração, descrição e dissertação.

Como muitas pesquisas revelam, ainda hoje o conceito de "dissertação escolar" é bastante arraigado no contexto escolar, mesmo com uma indicação oposta das propostas curriculares oficiais de ensino, que afirmam que o ensino da escrita deve ser fundamentado em práticas de linguagem autênticas e ancorado em gêneros de textos que circulam socialmente (BRASIL, 2017). Partindo da importância de formar alunos que atuem de forma crítica e consciente na sociedade, os documentos oficiais da educação (BRASIL, 2017) tomam os textos, em sua totalidade enunciativa, como unidades de ensino da língua portuguesa e, consequentemente, os gêneros textuais, como eixo central desse processo, a fim de se ampliar os discursos dos alunos para diferentes contextos.

É, pois, por conta dessa nova forma de conceber o ensino da língua, que os 
vestibulares vêm dando cada vez mais espaço para a noção de gêneros textuais/discursivos, tanto na avaliação da compreensão como da produção textual, em contraposição às tradicionais propostas baseadas nas tipologias textuais. No que se refere à avaliação da produção escrita, um gênero que tem se destacado é o artigo de opinião, uma vez que é um gênero que requer que os vestibulandos se posicionem diante de um tema social polêmico e atual.

De modo geral, nesses contextos de concursos vestibulares, o termo "redação" continua, mas com uma perspectiva discursiva, ancorada em práticas de linguagem, como é o caso da prova de seleção do vestibular da Universidade Estadual do Norte do Paraná (UENP) que, desde 2015, propõe que os candidatos produzam um artigo de opinião, a respeito de uma polêmica explicitada no comando da prova, como ferramenta de avaliação da produção escrita.

Partindo dessa problemática maior, relacionada ao ensino e aprendizagem da escrita, este trabalho tem como foco a produção de textos do gênero "artigo de opinião como redação de vestibular" (STRIQUER; BARROS, 2020) por candidatos do concurso vestibular 2018 da UENP. A partir desse escopo, este artigo se propõe a analisar como são articuladas as modalizações, no percurso enunciativo-argumentativo da escrita do artigo de opinião como redação de vestibular, bem como a influência do ato de modalizar o discurso na construção desse gênero, tendo como fundamento principal os estudos teórico-metodológicos do Interacionismo Sociodiscursivo (ISD - BRONCKART, 2003, 2006), sobretudo, no que se refere às suas noções de gêneros textuais e mecanismos enunciativos.

Esta pesquisa se configura como de natureza qualitativa (FLICK, 2004), de cunho documental (GIL, 2011), uma vez que o corpus de análise - redações do processo seletivo de 2018 da UENP - é compilado a partir de materiais não manipulados. A proposta de escrita das redações analisadas solicita que os candidatos produzam um artigo de opinião, assumindo o papel social de um leitor de jornal que intenciona publicar seu ponto de vista em relação à questão polêmica: "De modo geral, o ativismo nas redes sociais, ou ciberativismo, tem repercussões significativas na sociedade ou fica restrito ao mundo virtual?”.

O processo analítico é realizado a partir da sistematização do ISD para as modalizações, categoria essa incluída nos mecanismos enunciativos (BRONCKART, 2003). São, a princípio, categorizados os tipos de modalização encontrados, para, em seguida, serem selecionados excertos que possam exemplificar os resultados encontrados, a partir de sinalizações das principais ocorrências do corpus da pesquisa, a fim de se promover reflexões sobre a escrita de artigos de opinião como redação de vestibular. 
O trabalho faz parte do projeto de pesquisa "A escrita de textos argumentativos em contexto de vestibular”, desenvolvido na UENP, aprovado pelo Comitê de Ética em Pesquisa com Seres Humanos, por meio do parecer consubstanciado CAAE ${ }^{\circ}$ 95902418.4.0000.812.

\section{Base teórica da pesquisa: Interacionismo Sociodiscursivo (ISD)}

O Interacionismo Sociodiscursivo (ISD), proposto por Bronckart $(2003,2006)$, referese a uma corrente teórica, de base discursiva, que tem como uma de suas fontes primárias o Interacionismo Social vygotskyano, do qual o ISD adota, sobretudo, a tese de que o processo de individualização dos sujeitos é diretamente dependente do seu processo de socialização.

Por ter uma base discursiva, Bronckart (2006, p. 10) ressalta que "A especificidade do ISD é a de postular que o problema da linguagem é absolutamente central ou decisivo para essa ciência do humano" ". Para o autor e demais pesquisadores do Grupo de Genebra, a linguagem é vista como uma atividade social que parte da necessidade que o homem possui de agir e interagir em seu meio, nesse sentido, a atividade de linguagem, para o ISD, é sempre vista do ponto de vista social-coletivo. Tais atividades se ancoram em ações de linguagem situadas, as quais se materializam em textos/discursos que sempre se configuram em algum gênero de texto, a fim de suprir as necessidades de comunicação humana. Por exemplo, na atividade social acadêmica, se um estudante perde uma prova e precisa comunicar o ocorrido ao professor, faz-se necessário que ele empreenda uma ação de linguagem elaborando um texto, que pode ser, por exemplo, um requerimento de segunda chamada (gênero de texto).

Nesse sentido, Barros e Nascimento (2008, p. 45) apontam que "todo texto é, pois, fruto de uma ação de linguagem [...]. Da mesma forma, todo texto só é concretizado por meio da apropriação de um gênero, ou seja, qualquer texto empírico configura-se em um modelo de gênero". Desse modo, pode-se dizer que toda interação social requer a apropriação de um gênero, o qual deve ser adaptado de acordo com o contexto de interação. Assim, como afirma Bronckart (2003), a apropriação dos gêneros é fundamental para a socialização e para as atividades comunicativas.

Para dar conta da descrição das práticas de linguagem que permeiam nossa sociedade, Bronckart (2003) elabora um quadro com categorias para análise de textos/gêneros, composto por dois grandes pilares: o contexto/condições de produção e a arquitetura interna dos textos. Essa última é dividida em três níveis: 1) a infraestrutura geral do texto; 2) os mecanismos de

\footnotetext{
${ }^{4}$ Ciência do humano é como Bronckart (2006) rotula o ISD.
} 
textualização; 3 ) os mecanismos enunciativos. A infraestrutura geral do texto envolve o plano textual global, os tipos de discurso e as formas de planificação textual, ou seja, os tipos de sequência. Os mecanismos de textualização são responsáveis por dar coerência articulatória ao texto, os quais são analisados, pelo ISD, por três categorias: a conexão, a coesão nominal e a coesão verbal. Já os mecanismos enunciativos visam dar coerência pragmática ao texto, e envolvem o gerenciamento das vozes e a modalização dos enunciados.

O quadro a seguir sintetiza as categorias sistematizadas por Bronckart (2003) para a análise das práticas de linguagem que se materializam em textos/gêneros:

Quadro 1 - Categorias de análise da arquitetura interna do texto

\begin{tabular}{|c|c|c|}
\hline $\begin{array}{c}\text { INFRAESTRUTURA GERAL } \\
\text { DO TEXTO }\end{array}$ & $\begin{array}{c}\text { MECANISMOS DE } \\
\text { TEXTUALIZAÇÃO }\end{array}$ & $\begin{array}{c}\text { MECANISMOS } \\
\text { ENUNCIATIVOS }\end{array}$ \\
\hline 1. Plano textual global & 1. Conexão & 1. Gerenciamento das vozes \\
\hline 2. Tipos de discursos & 2. Coesão nominal & \multirow{2}{*}{ 2. Modalizações dos enunciados } \\
\hline 3. Tipos de sequências & 3. Coesão verbal & \\
\hline
\end{tabular}

Fonte: as autoras, adaptado de Bronckart (2003).

Neste trabalho, focalizamos apenas o nível dos mecanismos enunciativos, com o intuito de analisar como são articuladas as modalizações nos artigos de opinião como redação de vestibular produzidos por candidatos do concurso 2018 da UENP.

\subsection{Mecanismos enunciativos: as modalizações dos discursos}

De acordo com Bronckart (2003), o nível dos mecanismos enunciativos está relacionado à coerência pragmática do texto, tanto no que se refere às avaliações do agenteprodutor (modalizações) quanto às instâncias enunciativas que são mobilizadas (vozes enunciativas): os mecanismos enunciativos explicitam "as diversas avaliações (julgamentos, opiniões, sentimentos) que podem ser formuladas a respeito de um ou outro conteúdo temático e [...] as próprias fontes dessas avaliações” (BRONCKART, 2003, p. 319).

Há um agente empírico, segundo Bronckart (2003), que realiza a ação de linguagem, que pode ser associado à noção mais genérica de "autor". Entretanto, esse agente-produtor, ao criar um mundo discursivo (mundo virtual da linguagem) mobiliza um conjunto de vozes para gerenciar os atos enunciativos que compõem o texto. Na perspectiva teórica do ISD, as noções de mundos discursivos (mundo do NARRAR e mundo do EXPOR) e das instâncias de enunciação desses mundos dão suporte à compreensão de como se realiza a coerência 
pragmática no âmbito discursivo. Bronckart (2003), em seus estudos, caracterizou três instâncias enunciativas: 1) o textualizador, 2) o narrador, 3) o expositor. O textualizador seria a instância geral, à qual estariam atrelados tanto o narrador, encarregado pelo gerenciamento dos mundos discursivos da ordem do narrar, como o expositor, responsável pelo gerenciamento dos mundos discursivos da ordem do expor (BRONCKART, 2003).

Segundo Bronckart (2003, p. 326 - grifos do autor), “As modalizações têm como finalidade geral traduzir, a partir de qualquer voz enunciativa, os diversos comentários ou avaliações formulados a respeito de alguns elementos do conteúdo temático".

As modalizações estão relacionadas aos aspectos configuracionais do texto, e contribuem para o estabelecimento da coerência pragmática, ajudando o destinatário a interpretar seu conteúdo temático. Em seus estudos, Bronckart (2003) priorizou quatro funções de modalização: lógicas, deônticas, apreciativas e pragmáticas; as quais descrevemos a seguir.

As modalizações lógicas consistem em uma avaliação de alguns elementos do conteúdo temático, com base em critérios e/ou conhecimentos elaborados e organizados a partir das coordenadas formais que definem o mundo objetivo; e apresentam os elementos de seu conteúdo do ponto de vista de suas condições de verdade, como fatos atestados (ou certos) ou possíveis, eventuais, necessários. Estruturas oracionais como "é evidente que" e advérbios como "necessariamente" ou "talvez" são exemplos de unidades linguísticas que exercem a função modalizadora lógica.

Já as modalizações deônticas correspondem a avaliações de alguns elementos do conteúdo temático, ancoradas nos valores, opiniões e regras pertinentes ao mundo social, apresentando os elementos do conteúdo como parte do domínio do direito, da obrigação social e/ou da conformidade com as normas em uso. É comum, nessa função, o uso de termos como "pode", “deve", “é preciso que".

As modalizações apreciativas, por sua vez, dizem respeito às avaliações procedentes do mundo subjetivo da voz que é fonte desse julgamento, apresentando-os como benéficos, prejudiciais, infelizes, etc., de acordo com o ponto de vista da entidade avaliadora. Temos, nessa categoria, advérbios como "felizmente" e "infelizmente", os quais demonstram a apreciação da fonte de julgamento.

As modalizações pragmáticas visam explicitar alguns aspectos da responsabilidade de uma entidade constitutiva do conteúdo temático (personagem, grupo, instituição, etc.) que detém a agentividade da ação, atribuindo a ela intenções, razões, ou ainda, capacidades de ação. Nesse caso, temos como exemplo qualquer tipo de unidade linguística que esteja 
imputada a outras vozes, que não seja a do autor.

Bronckart (2003), a fim de sistematizar a análise das modalizações, traz quatro subconjuntos de unidades linguísticas que caracterizam, de forma prototípica, as marcações das modalizações:

1) os tempos verbais do modo condicional (futuro do pretérito do modo indicativo);

2) os auxiliares de modo (querer, dever, ser necessário, poder, crer, pensar, gostar de, desejar, ser obrigado a, ser constrangido a, etc.);

3) os advérbios e locuções adverbiais (certamente, provavelmente, evidentemente, talvez, sem dúvida, felizmente, entre outras);

4) as orações impessoais que regem uma oração subordinada completiva (é provável que..., é lamentável que..., sem dúvida que..., etc.).

A seguir, investigamos como são articuladas as modalizações no processo de argumentação nos artigos de opinião produzidos como redação do vestibular da UENP. Antes, porém, trazemos uma síntese da pesquisa bibliográfica acerca do gênero "artigo de opinião" e seu funcionamento em contexto de vestibular.

\section{0 gênero "artigo de opinião" e sua inserção como referência em redações de vestibular}

O artigo de opinião é um gênero da esfera jornalística que tem a argumentação como base para a sua composição. Trata-se de um gênero pertencente à ordem do argumentar, uma vez que se fundamenta na defesa de um ponto de vista em relação a uma questão polêmica (cf. RANGEL; GAGLIARDI; AMARAL, 2010).

Melo (1985 apud BONINI, 2003, p. 213) classifica os gêneros do jornal de acordo com a intencionalidade e a natureza estrutural dos relatos. Nesta última classificação, o autor aponta duas categorias: o jornalismo opinativo e o jornalismo informativo. Nesse sentido, o gênero artigo de opinião estaria atrelado ao jornalismo opinativo, embora essa dicotomia seja hoje muito questionada dentro do campo jornalístico, uma vez que nem sempre os discursos se dividem tão claramente entre essas duas instâncias (cf. BARROS, 2015), em razão do imbricamento entre informação e opinião, que acaba tirando a "pureza" discursiva dos textos tradicionalmente caracterizados como "informativos".

O artigo de opinião "consiste em um gênero textual que se vale da argumentação para analisar, avaliar e responder a uma questão controversa" (KÖCHE, 2012, p. 33). Tem como 
objetivo "convencer o outro sobre determinada ideia, influenciando-o e transformando seus valores por meio da argumentação a favor de uma posição, e de refutação de possíveis opiniões” (KÖCHE, 2012, p. 33). Percebemos, nessas perspectivas, a concepção de que o artigo não apenas discute sobre o tema polêmico gerador, mas usa os recursos da argumentação para convencer o leitor sobre determinada ideia defendida pelo agente-produtor do texto.

Já Rodrigues (2001, p. 163) incorpora outro aspecto ao gênero, o fato de o artigo apresentar uma resposta valorativa diante dos acontecimentos sociais. Nesse sentido, "o artigo é um gênero que se caracteriza discursivamente como uma réplica dialógica a esses acontecimentos sociais, diante dos quais o autor se posiciona".

Com relação os aspectos que determinam a "relativa estabilidade" do artigo de opinião, Zanini (2017) destaca que é um gênero da esfera jornalística que apresenta algumas características prototípicas, entre elas: a) o objetivo de convencer o leitor a aceitar a opinião do autor e/ou articulista, como é denominado no meio jornalístico; b) o assunto refere-se a uma questão polêmica atual; c) apresenta-se, normalmente, em primeira pessoa do singular ou do plural.

Para Zanini (2017), o produtor de um artigo de opinião deve levar em consideração a mesma organização estrutural de outros gêneros argumentativos: a) título, procurando destacar o objetivo do autor diante do fato a ser evidenciado; b) introdução, buscando introduzir o assunto a ser discutido; c) expansão, entendida como o desenvolvimento do texto, na qual se imbricam o ponto de vista e os argumentos do autor; d) conclusão, que propõe o fechamento das ideias expostas ao longo do texto. A autora pontua a assinatura como último elemento estruturante de um artigo de opinião, no entanto, em contexto de vestibular, a assinatura é proibida, uma vez que preza pela não identificação do candidato.

De forma geral, os autores que tomam esse gênero como objeto de estudo colocam a argumentação como uma de suas principais características. O produtor do texto, também chamado de articulista, deve se posicionar perante a uma questão polêmica e convencer o leitor a respeito do seu ponto de vista, por meio da apresentação de argumentos e contraargumentos. Vale ressaltar que uma questão só é polêmica se gerar discussão social, ou seja, se houver diferentes posicionamentos (a favor e contra).

Nesse sentido, podemos compreender a importância do artigo de opinião na formação crítica dos indivíduos, pois ao ler um texto desse gênero, o sujeito pode se deparar com um posicionamento diferente do seu, o que pode levá-lo a refletir sobre suas convicções, estimulando a proposição de contra-argumentos para tornar sua tese mais fortalecida e, outras 
vezes, fazendo com que o ponto de vista assumido se altere - objetivo central da argumentação. Isso porque o articulista, no processo de produção de um artigo de opinião, precisa trabalhar sua criticidade para expor o seu ponto de vista e justificá-lo para convencer o seu leitor a aderir a sua tese.

Considerando a importância de se trabalhar com gêneros textuais na escola e, também, o caráter formador que o artigo de opinião possui, é comum o trabalho com esse gênero, sobretudo no Ensino Médio, com o intuito de desenvolver e aprimorar a argumentação dos jovens. Nesse sentido, podemos trazer como exemplo a Olimpíada de Língua Portuguesa que, em seu concurso em nível nacional, incorporam o gênero artigo de opinião como objeto de produção de textos nas séries finais do Ensino Médio ( $2^{\circ}$ e $3^{\circ}$ ano). A abordagem desse gênero pela Olimpíada de Língua Portuguesa é relevante, pois o Programa vai muito além de um concurso de redações, já que disponibiliza para o professor um material planificado a partir da metodologia das sequências didáticas de gêneros criada por pesquisadores do ISD (cf. SCHNEUWLY; DOLZ, 2004), com oficinas práticas voltadas para a apropriação desse gênero pelos jovens, tanto no âmbito da leitura como da produção textual.

Em seu material de apoio ao professor, o Programa traz, como ponto central da definição de artigo de opinião, o fato de esse ser um gênero que possui a finalidade de defender uma tese, a qual deve ser fundamentada com argumentos coerentes. Nesse sentido, o articulista assume um posicionamento e procura defender seu ponto de vista, a fim de contribuir para a adesão do leitor à posição defendida. Nesta pesquisa, optamos por privilegiar a definição do artigo de opinião apresentada pelos materiais da Olimpíada, ou seja, um gênero que fundamenta-se na defesa de uma tese, uma vez que essa é a definição adotada também pelo vestibular da UENP, foco da nossa análise.

Entretanto, o gênero que serve como objeto de nossas análises não é exatamente o artigo de opinião produzido no interior da esfera jornalística. Nosso foco é um gênero em contexto de avaliação vestibular. Assim como Striquer e Barros (2020), compreendemos que, nesse contexto, já não podemos mais falar unicamente de artigo de opinião, mas artigo de opinião como redação de vestibular, o qual precisa ser visto como

[...] um novo gênero discursivo/textual, visto que, ao deslocar-se do seu contexto natural de produção, do campo jornalístico, os objetivos discursivos e os elementos que formam o contexto de produção não são os mesmos: o autor assume outros papéis sociais; os destinatários são outros; o tempo e espaço de produção também, consequentemente, os elementos linguísticodiscursivos refletem esses aspectos (STRIQUER; BARROS, 2020, no prelo).

Ou seja, em contexto de vestibular temos uma dubiedade contextual que reflete o 
conflito de representações pelo qual passa o candidato ao produzir o seu texto. Primeiramente, a situação virtual simulada pelo comando da redação que, no caso das redações do vestibular da UENP, representa a escrita de um artigo de opinião por um leitor que deseja publicar no jornal seu ponto de vista frente a uma questão polêmica. Do outro lado, temos a situação real de produção, representada, nesse caso, pela escrita como ferramenta de avaliação em contexto de vestibular, com propósito de ingresso na universidade.

O artigo de opinião como redação de vestibular apresenta, dessa forma, dois interlocutores: um virtual e outro real (SILVA, 2018). O virtual são os leitores do jornal; o real, a banca corretora, formada por especialistas. Da mesma forma, há uma duplicidade em relação aos papeis desempenhados pelo enunciador do texto: ora ele assume o papel de um leitor de jornal que intenciona convencer os demais assinantes a aderirem a seu ponto de vista, ora incorpora um candidato que deseja uma vaga na universidade e, para tanto, precisa mostrar que domina o gênero solicitado como referência da redação.

Essa constatação é importante para nossa pesquisa, uma vez que, como ressalta Barros e Nascimento (2008, p. 166), “não há como fazer uma análise linguística das modalizações sem levar em consideração o contexto de produção textual, ou seja, quais as representações da situação que serviram de base de orientação para o ato da textualização".

\section{Apresentação do corpus da pesquisa}

Para a análise das articulações das modalizações nos textos dos vestibulandos utilizamos exemplares das redações do processo seletivo de 2018 da UENP, cuja proposta solicitava que o candidato produzisse um artigo de opinião, assumindo o papel social de um leitor de jornal que intencionava publicar seu ponto de vista em relação à questão polêmica: "De modo geral, o ativismo nas redes sociais, ou ciberativismo, tem repercussões significativas na sociedade ou fica restrito ao mundo virtual?” (UENP, 2018).

O corpus selecionado para análise abrangeu dois grupos de textos, distintos quanto às notas que obtiveram na correção do vestibular: de 3,1 a 5,0 e de 7,1 a 8,5. Esses grupos representam, de forma geral, as mais baixas e as mais altas notas concedidas pela banca como resultado das avaliações realizadas. No processo seletivo, a redação com nota inferior a 3,0 é desclassificada; e no referido processo não houve notas superiores a 8,5. Nossa intenção não foi verificar se esses grupos apresentavam diferenças quanto à abordagem da modalização, mas apenas diversificar a amostragem, a fim de obter resultados mais representativos do gênero. Como já apresentado, nosso objetivo é analisar como são articuladas as modalizações 
nos processos de argumentação desses textos e a influência do ato de modalizar o discurso na construção do gênero "artigo de opinião como redação de vestibular" (STRIQUER; BARROS, 2020). Na sequência, trazemos a descrição do corpus analisado, selecionado, dentro dos dois grupos mencionados, de forma aleatória.

Quadro 2 - Descrição do corpus

\begin{tabular}{|c|c|c|}
\hline $\begin{array}{c}\text { GRUPOS: } \\
\text { NOTAS }\end{array}$ & $\begin{array}{c}\text { CÓDIGO DO } \\
\text { CORPUS PARAA } \\
\text { PESQUISA }\end{array}$ & TÍTULOS DOS ARTIGOS DE OPINIÃO \\
\hline \multirow{6}{*}{$\begin{array}{l}\text { Grupo } 1: \\
3,1 \text { a } 5,0\end{array}$} & AO1-G1 & "Os tempos mudaram" \\
\hline & $\mathrm{AO} 2-\mathrm{G} 1$ & "A prática da internet nas ruas" \\
\hline & AO3-G1 & "Redes sociais, a nova era do agora!" \\
\hline & $\mathrm{AO} 4-\mathrm{G} 1$ & "Mundo virtual" \\
\hline & AO5-G1 & "Prós e contras das redes sociais" \\
\hline & AO6-G1 & "Será que estamos aproveitando algo tão magnífico direito?" \\
\hline \multirow{6}{*}{$\begin{array}{l}\text { Grupo } 2: \\
7,1 \text { a } 8,5\end{array}$} & AO7-G2 & "O Outro Lado do Ativismo" \\
\hline & $\mathrm{AO} 8-\mathrm{G} 2$ & "Campo de luta de debates" \\
\hline & AO9-G2 & "Como os grandes impérios seriam construídos virtualmente?" \\
\hline & $\mathrm{AO} 10-\mathrm{G} 2$ & "A modernização da retórica de Sócrates" \\
\hline & $\mathrm{AO} 11-\mathrm{G} 2$ & "Ciberativismo: o uso exige cautela" \\
\hline & AO12-G2 & "A influência das redes sociais nas ações da sociedade" \\
\hline
\end{tabular}

Fonte: as autoras.

Vale ressaltar que os textos do corpus são mobilizados à medida que a análise vai exigindo. Nesse sentido, apresentamos trechos textuais que consideramos essenciais para a ilustração dos resultados, com destaque em negrito das unidades linguísticas modalizadoras. Além disso, transcrevemos os trechos da maneira em que foram textualizados, mesmo que contenham erros ortográficos ou gramaticais, a fim de manter a integralidade dos originais.

\section{A articulação das modalizações nos artigos de opinião como redação de vestibular}

Nossa análise procurou explorar as quatro modalizações categorizadas por Bronckart (2003): lógicas, deônticas, apreciativas e pragmáticas. Nesse sentido, procuramos comparar as diferentes estratégias de argumentação. A primeira constatação relaciona-se ao fato de que em todos os textos selecionados, tanto os do grupo 1 como do 2 , há a mobilização de unidades linguísticas modalizadoras do discurso argumentativo. 
As modalizações lógicas, voltadas para avaliações da ordem "verdade", são umas das mais comuns em nosso corpus. Na maioria das vezes, os agentes-produtores se valem de expressões como “torna-se evidente”, “é notório” para dar credibilidade à argumentação, como nos fragmentos a seguir. Nesses, os autores buscam responder à questão polêmica da proposta, argumentando sobre a força que o ativismo tem nas redes sociais, modalizando o discurso de forma a apresentar as informações como fatos atestados, imputados da "verdade".

(1) Em nossos dias, o ativismo se apresenta com "aparência" nova em diversos aspectos, como na utilização de novos recursos. O desenvolvimento da tecnologia permitiu que os adeptos de ideologias semelhantes se organizassem por meio das redes sociais a fim de disseminar suas ideias. Entretanto surge o questionamento da eficácia desse meio para a mobilização social. Portanto, torna-se evidente a devida preocupação à respeito do tema (AO11-G2).

(2) $\boldsymbol{E}$ notório que praticamente todo o ativismo é restrito ao campo virtual. Tome como exemplo um evento de manifestação política no facebook, o número de confirmados é astronômico, porém, fisicamente é ridículo, consideradas as proporções (AO9-G2).

(3) O ativismo nas redes sociais tem percussões significativas na sociedade, informações são compartilhadas rapidamente, notícias, as redes sociais podem de certa forma fazer as pessoas se unirem com um mesmo propósito. Entretanto, é notável considerar que algumas realmente só mostram atitude virtualmente, mas podem ser encorajadas vendo nas próprias redes sociais as pessoas que realmente fazem (AO12-G2).

No fragmento 1, o autor argumenta sobre o ativismo e sua eficácia para mobilizações sociais e faz uso do termo "torna-se evidente" para demonstrar que a preocupação a respeito desses temas é óbvia. É, também, uma forma de dar credibilidade à questão polêmica proposta pelo vestibular, a qual indaga se o ativismo nas redes sociais repercute fora do mundo virtual ou não. Ao dizer que "torna-se evidente a preocupação a respeito do tema", o autor também reafirma a relevância do tema trazido pelo processo seletivo.

No fragmento 2, o autor, ao defender que o ativismo não tem repercussões fora das redes sociais, usa o modalizador lógico "é notório" para atestar a verdade da afirmação, no entanto, mobiliza o advérbio de modo "praticamente", que demonstra certa cautela do autor em relação à informação apresentada como "verdade", uma vez que é diferente dizer "todo ativismo é restrito..." de "praticamente todo ativismo é restrito...". O "praticamente" isenta o autor de possíveis críticas em relação à veracidade da afirmação, o que demonstra uma modalização do discurso da ordem da "verdade aproximada".

No fragmento 3 , consideramos que o candidato pode ter gerado uma confusão entre os 
sentidos das palavras "notável" e "notório", uma vez que a primeira corresponde a algo digno de atenção, apreciável, e a segunda refere-se àquilo que é amplamente conhecido, evidente. Nesse caso, considerando que o vestibulando quis dizer "é notório" e errou o termo, entendemos como uma tentativa de argumentar que as atitudes de algumas pessoas ficam restritas apenas ao mundo virtual, como se fosse um fato que pode ser percebido por todos. Levando em consideração essa perspectiva, podemos perceber que há um diferencial: o autor traz uma possível "solução" colocando que, por meio das redes sociais, tais pessoas podem ser estimuladas a se manifestarem na vida real.

As modalizações lógicas voltadas para a ordem do provável, isto é, de exposição de fatos como possíveis ou incertos também são representativas no nosso corpus. Nesse caso, os candidatos não apresentam os fatos como verdades absolutas, mas optam por "fugirem" de tais verdades, apresentando as situações de forma incerta, consequentemente, modalizando o seu discurso. Assim, apresentam seu posicionamento, mas abrindo um diálogo com o leitor que pode pensar diferente. Como destacado anteriormente, no artigo de opinião em contexto de vestibular, há uma dubiedade de interlocutores: um virtual (leitores de jornal), outro real (banca de especialistas) (STRIQUER; BARROS, 2020). Assim, em última instância, o que o autor da redação pretende é conquistar uma vaga e não, literalmente, convencer seu leitor de que seu ponto de vista é certo. Isso reflete em seu discurso "atenuado", como podemos verificar nos trechos a seguir:

(4) Pois assim se toda a sociedade lutar pelo mesmo objetivo é provável obter pela conquista (AO2-G1).

(5) As ideias opostas "não se atraem” nas redes, pois o debate dá lugar a palavras de baixo calão e ódio gratuito. Esse talvez seja um dos motivos pelos quais as pessoas tenham mais amigos que pensam da mesma maneira. $O$ medo de alguém não concordar, possa ser, na verdade, uma medida de cautela contra a selvageria (AO7$\mathrm{G} 2$ ).

(6) Talvez, na época antiga, nos primórdios da filosofia, tudo fosse mais harmonioso (AO7-G2).

A mobilização de modalizações deônticas, ou seja, aquelas apoiadas em valores que regem o mundo social e que apresentam o conteúdo temático como sendo da ordem do direito, das normas, da obrigação social, também é recorrente em nosso corpus. Nos fragmentos a seguir, verificamos o uso de expressões "é necessário" e "é preciso" e suas variantes que, nesses casos, demonstram a necessidade de que alguma ação social aconteça para "solucionar" a problemática envolvida na polêmica trazida pelo texto. 
(9) É necessário ter a consciência que nossas ideologias necessitam serem mantidas nas ruas (AO2-G1).

(10) Para isso, é preciso a exposição e disseminação das propostas para a comunidade por meio de campanhas e protestos com intuito de repercussão, sendo necessária a não restrição somente ao cenário digital (AO11-G2).

(11) Diante dos argumentos supracitados, medidas são necessárias para a resolução desse impasse (AO11-G2).

(12) Porém, é necessário termos cautela para usufruirmos deste "passa-tempo", e não transformá-la em vício (AO3-G1).

(13) Acredito que as redes sociais de fato auxiliam os grupos, tendo em vista a importância da esfera virtual em nosso mundo. Porém, é necessário o uso desse meio de forma correta para a livre expressão dos movimentos e sua real concretização na sociedade, com intuito de estabelecer conquistas sociais e políticas (AO11-G2).

Os exemplos demostram que a argumentação do vestibulando perpassa, em grande parte, pela necessidade de indicar a resolução dos problemas levantados como uma obrigação social. Essa obrigação ora está inserida no âmbito do coletivo social, momento em que o agente-produtor se integra no discurso, utilizando, para tanto, a primeira pessoa do plural (excertos 9 e 12), ora voltada às instâncias específicas (Governos, por exemplo) ou entidades genéricas, como no fragmento 10 e 11. No excerto 10, por exemplo, o ato de expor e disseminar reivindicações é trazido como uma necessidade genérica, não imputada a um agente específico.

Vale ressaltar, também, que esses trechos de modalizações deônticas estão situados na conclusão do artigo de opinião. Tal aspecto remete muito a um dos critérios do Exame Nacional do Ensino Médio (ENEM), no qual é exigido que os alunos elaborem, como conclusão do seu "texto dissertativo-argumentativo", uma proposta de intervenção para o problema. A semelhança discursiva entre o gênero "artigo de opinião como redação de vestibular" e o texto solicitado pelo ENEM, ambos planificados a partir da sequência argumentativa (BRONCKART, 2003), faz com que os vestibulandos busquem referências nos treinamentos voltados para a escrita do texto dissertativo-argumentativo do ENEM e apontem, na conclusão de seus artigos de opinião, soluções para a questão polêmica proposta, utilizando, para tanto, modalizações deônticas. Essa evidência mostra como o artigo de opinião como redação de vestibular está adquirindo uma nova estrutura composicional, diferente daquela prototípica do gênero de referência social. Logo, se distanciando da estrutura apresentada por Zanini (2017). 
Ainda no que se refere às modalizações deônticas, identificamos o uso do verbo auxiliar "poder", como forma de apresentar "conselhos" ancorados em valores que permeiam o mundo social. Por exemplo, em nossa sociedade há uma fala muito presente de que se alguém passa muito tempo na internet "pode" viciar-se (excerto 8). O uso dessas modalizações relaciona-se também a obrigações que estão postas na sociedade, como no excerto 7, em que o auxiliar "pode" modaliza uma oração adversativa introduzida por "mas cuidado", revelando uma espécie de "alerta social".

(7) Existe várias outras maneiras de se beneficiar, mas cuidado, pois ela pode se tornar algo ruim a qualquer momento (AO5-G1).

(8) Cuidado pois isso pode se transformar em vício (AO5-G1).

Outra unidade linguística muito frequente, relacionada às modalizações deônticas, é o verbo auxiliar "dever", quando voltado ao domínio das normas ou obrigação social, ou seja, representando algo que é preciso ser feito por todos, por isso o uso frequente da primeira pessoa do plural - “devemos". Vejamos nos trechos a seguir:

(14) Também devemos fazer nosso papel na sociedade, ajudar um doente com roupa, alimento, cobertas, e até desde que seja um cachorro desaparecido ou uma pessoa desaparecida temos que ajudar também, devemos conciliar os dois rede social com sociedade porque hoje em dia um não vive sem o outro (AO1-G1).

(15) Além disso, devemos tomar cuidado para não criarmos bolhas sociais, ou seja, só escutarmos a opinião de quem concorda com a nossa e anularmos as outras (AO10$\mathrm{G} 2)$.

(16) Portanto, devemos ter em mente que a diferença não é só debater, adquirir ideias e chegarem em uma conclusão, e sim colocá-las em práticas, pois colocando-as podemos obter pela diferença (AO2-G1).

(17) O que devemos fazer é por em prática nossas ideias e lutar pelo que queremos, reunindo com os demais com a mesma opinião e tentar mudar o que foi discutido (AO6-G1).

(18) Todavia, alguns cuidados devem ser tomados nas redes sociais (AO10-G2).

Nesses fragmentos, notamos que os candidatos apresentam algumas atitudes que precisam ser tomadas, como se estivessem relacionadas ao nosso "papel" na sociedade: dos autores dos textos, de seus leitores, e de toda a comunidade. Para argumentar a respeito dessa “obrigação social”, é comum que os agentes-produtores utilizem a primeira pessoa do plural ("devemos"), colocando-se como participante direto do assunto em debate ou pelo menos simulando participar. 
As modalizações apreciativas, por sua vez, não são muito expressivas em nosso corpus. No decorrer da análise, encontramos somente dois textos com a mobilização desse tipo de modalização, marcados pelo uso do advérbio de modo "infelizmente", conforme mostram os excertos a seguir:

(19) A internet é uma ótima ferramenta para tentarem obterem pela diferença. Ela consiste ser um ótimo recurso procurado para fazerem manifestações e protestos. Mas, infelizmente, só contém iniciativa nas redes (AO2-G1).

(20) Ademais, é coerente ressaltar que tal ferramenta abre espaço para um campo fértil de convergências e divergências de ideais políticos que - infelizmente - se consolidam em "bolhas" ou "espelhos" (AO8-G2).

No fragmento 19, fica evidente a resposta do autor à questão polêmica proposta pelo vestibular: o ativismo não repercute fora das redes sociais. Com o uso do advérbio “infelizmente", é possível perceber o julgamento subjetivo do agente-produtor. Já o fragmento 20 apresenta uma avaliação do vestibulando para o fato de que a internet dá espaço para ideais políticos convergentes e divergentes, os quais criam "bolhas" ou "espelhos". A modalização apreciativa tem o poder de explicitar a subjetividade do autor; é quando mais nitidamente se percebe a "voz do autor" (cf. BRONCKART, 2003). Os trechos analisados poderiam ser escritos sem o "infelizmente", sem prejuízo gramatical, porém, ao inserir essa unidade modalizadora no texto, o discurso toma outro aspecto, pois revela a avaliação do agenteprodutor em relação à proposição enunciada. Na textualização do advérbio de modo “infelizmente", os vestibulandos não abrem mão do uso da vírgula ou outra notação gráfica, mesmo sendo esse um procedimento facultativo do ponto de vista gramatical. Isso mostra como essa modalização é tomada como importante para a construção da argumentação, uma vez que da forma como foi textualizada obriga-se o leitor a pausar a leitura, dando destaque à avaliação apreciativa.

Outra constatação está relacionada com o excerto a seguir

É notável a importância desses movimentos para a construção justa da sociedade, pois por intermédio deles que o homem foi conquistando seus direitos (AO11-G2).

Conforme mencionamos, a palavra "notável" diz respeito àquilo que é digno de atenção, admirável. Nesse sentido, entendemos que o uso do termo, nesse caso, pode ser classificado como uma modalização apreciativa, pois o autor dá a entender que a importância dos movimentos sociais é digna de atenção.

A última modalização a ser analisada, a pragmática, refere-se a alguns aspectos da 
responsabilidade de uma entidade enunciativa que é mobilizada no texto pelo agente-produtor como uma "voz outra". Durante a análise, verificamos que tal modalização também não é muito recorrente em nosso corpus. Outra constatação diz respeito ao fato de que quando o candidato cita uma voz de personagem (BRONCKART, 2003), os verbos do dizer são, na sua maioria, neutros, ou seja, sem carga valorativa. Em nosso corpus, encontramos o uso frequente do próprio verbo "dizer". Os textos analisados trazem a inserção de vozes de personagens, porém, sem que o agente-produtor do texto traga algum elemento modalizador imputado a essas vozes, como exemplificam os fragmentos a seguir:

(21) Em nossa sociedade globalizada caracterizada pela efemeridade de pensamentos e ideais, como diz o sociólogo Bauman, é inerente a divergência de pensamentos e a busca constante por reivindicações políticas e sociais da população (AO11-G2).

(22) Não obstante, tal tecnologia deixa a desejar uma ação ativa que não se resuma a textões e desabafos passivos; até porque, como diria o grande Renato Russo, o Brasil é um país do futuro, porque esse futuro - ainda que em pleno século XXI - nunca chega (AO8-G2).

(23) Pessoas mais velhas dizem que essa integração nos modos de se relacionar com a família, e sim eles estão certos, pois jovens acabam se afastando de todos seus familiares para se entregar apenas para suas redes sociais (AO5-G1).

(24) Como disse o filósofo William James "o ser humano pode alterar sua vida alterando suas atitudes mentais" (AO4-G1).

De modo geral, nossa análise evidencia que é muito comum a mobilização de modalizações lógicas e deônticas nos artigos de opinião como redação de vestibular, ao passo que as modalizações apreciativas e pragmáticas são pouco expressivas.

Como vimos, as modalizações apreciativas são marcadas por uma avaliação procedente do mundo subjetivo do agente-produtor. Levando em consideração que só foram encontradas três modalizações desta categoria, ficou evidente que os candidatos evitam deixar marcas que evidenciam a subjetividade de suas avaliações. Essas acontecem, porém, sem serem modalizadas com termos como "felizmente" ou "infelizmente" que revelam a subjetividade autoral.

Quanto às modalizações pragmáticas, pela sua inexistência no corpus, concluímos que os vestibulandos procuram argumentar empregando vozes de autoridade (de personagens, na teoria bronckartiana), de maneira mais neutra, por meio do uso de verbos do dizer sem carga valorativa, por isso a mobilização frequente do próprio verbo "dizer" em contraposição a outros como "afirmar", "ressaltar", "ponderar", "argumentar".

Já nas modalizações lógicas, os agentes-produtores apresentam as informações como 
se fossem fatos atestados e/ou algo que todos (seus interlocutores) reconhecem como verdadeiro. Os exemplos demonstram isso: expressões como "é notório" ou "é notável" dão a entender que qualquer um pode perceber a verdade do que foi dito. Consideramos que o uso desses elementos modalizadores pode estar relacionado à própria proposta feita pelo vestibular: por se tratar de um tema atual e polêmico, é comum que os vestibulandos também considerem que se trata de algo amplamente conhecido.

Nas modalizações deônticas, os candidatos lidam com valores, regras e opiniões regidas pelo mundo social para a construção de seus argumentos - é o caso do uso de termos/expressões como "é necessário", “devem” e outros expostos na análise. Na maioria das vezes, é possível perceber uma tentativa de expressar uma "obrigação social”, algo que deve ser feito e/ou que todos precisam fazer. A nosso ver, tais constatações se assemelham às proposições - característica muito prototípica do ENEM - na qual os alunos buscam trazer uma solução para o problema. No mesmo sentido, é comum a mobilização do verbo auxiliar “poder" e outras unidades linguísticas como "talvez", que indicam a possibilidade de que algo aconteça. Vimos que, em alguns casos, tais modalizadores são utilizados para servirem de "alerta" ao leitor: nessas situações, os articulistas tentam expressar "conselhos" para acontecimentos que podem vir a acontecer, amparados pelo discurso injuntivo. Já nos casos em que usam termos como "talvez", a ideia é demonstrar incerteza sobre aquilo que foi dito ou isentar o autor de possíveis críticas em relação à veracidade da afirmação.

\section{Considerações Finais}

Por meio da análise desenvolvida neste trabalho, foi possível perceber como as modalizações são articuladas por candidatos do vestibular da UENP 2018 ao produzirem a redação solicitada pelo concurso, essa tendo como referência o artigo de opinião jornalístico, mas constituindo-se como um novo gênero, o "artigo de opinião como redação do vestibular". Nosso intuito foi investigar em que medida os vestibulandos modalizam seus discursos ao produzirem esse gênero em específico,

Os resultados apontam que em todos os textos selecionados, tanto os do grupo 1 como do 2, há a mobilização de unidades linguísticas modalizadoras do discurso argumentativo. De forma mais específica, as modalizações lógicas são as mais comuns, as quais promovem que os candidatos apresentarem seus posicionamentos e os argumentos que os defendem como fatos atestados, verdadeiros. No mesmo sentido, são empregadas as lógicas voltadas à exposição de fatos como possíveis ou incertos, as quais se ligam ao fato de que, diferente da 
situação de jornal, o objetivo primeiro não é convencer seu leitor, no vestibular, o produtor da redação visa alcançar um bom desempenho, assim, atenua seu discurso, expondo se posicionamento como possível.

As modalizações deônticas também são muito presentes, e por estarem situadas mais na conclusão dos textos, indicam soluções para os problemas levantados na temática, em analogia ao que é exigido na redação exigida no ENEM. O emprego dos verbos auxiliares "poder" e "dever" confirma nossa interpretação, o candidato apresenta "conselhos" ancorados em valores que permeiam o mundo social; ou destaca uma ação como uma obrigação social de todos, inclusive dele mesmo, por exemplo, "Também devemos fazer nosso papel na sociedade...".

Por sua vez, as modalizações apreciativas raramente aparecem nos textos analisados, o que indica que os candidatos evitam deixar marcas da subjetividade em suas avaliações, enunciando mais como um coletivo, como se propõem em cursinhos preparatórios para o ENEM. Já as pragmáticas não tiverem nenhuma incidência no corpus analisado. Nesse sentido, as análises mostraram uma inserção enunciativa neutra de vozes de autoridade.

\section{Referências}

BARROS, E. M. D. A didatização do jornal impresso num contexto de formação docente. In: SIMELP - SIMPÓSIO MULDIAL DE ESTUDOS DA LÍNGUA PORTUGUESA, 5, 2015, Lecce, Itália. Anais... Università del Salento, 2015, p. 3953-3970.

BARROS, E. M. D.; NASCIMENTO, E. L. A relação entre a modalização e o processo global de estruturação do gênero crítica cinematográfica. InterteXto, Uberaba, v. 1, p. 159-185, jan./jun. 2008.

BONINI, A. Os gêneros do jornal: o que aponta a literatura da área de comunicação no Brasil? Linguagem em (Dis)curso, Tubarão, v. 4, n. 1, p. 205-231, 2003.

BRASIL. Ministério da Educação. Base Nacional Comum Curricular. Ensino Fundamental. Brasília: MEC/SEB, 2017.

BRONCKART, J. Atividade de linguagem, textos e discursos: por um interacionismo sóciodiscursivo. Tradução Anna Rachel Machado e Péricles Cunha. 2. reimpr. São Paulo: EDUC, 2003.

BRONCKART, J. Atividade de linguagem, discurso e desenvolvimento humano. Tradução Anna Rachel Machado; Maria Lucia Meirelles Matencio. Campinas, Mercado de Letras, 2006.

Melo, J. M. de. A opinião no jornalismo brasileiro. Petrópolis: Vozes, 1985.

SCHNEUWLY, B.; DOLZ, J. (org.). Gêneros orais e escritos na escola. Tradução e 
Organização Roxane Rojo e Glaís Cordeiro. Campinas: Mercado de Letras, 2004.

STRIQUER, M. S. D.; BARROS, E. M. D. O artigo de opinião como redação de vestibular: um olhar sobre a construção composicional do gênero. Línguas e Letras, 2020. (No prelo).

FLICK, U. Uma introdução à pesquisa qualitativa. Tradução Sandra Netz. 2. ed. Porto Alegre: Bookman, 2004.

GIL, A. C. Métodos e técnicas de pesquisa social. 6. ed. São Paulo: Cortez, 2011.

KÖCHE, V. S. Leitura e produção textual: gêneros textuais do argumentar e do expor. 3. ed. Petrópolis: Vozes, 2012.

RANGEL, E. O.; GAGLIARDI, E.; AMARAL, H. Pontos de vista: caderno do professor. São Paulo: Cenpec, 2010 (Coleção da Olimpíada).

RODRIGUES, R. H. A constituição e o funcionamento do gênero jornalístico artigo: cronotopo e dialogismo. 2001. 356f. Tese (Doutorado em Linguística Aplicada e Estudos da Linguagem) - Pontíficia Universidade Católica de São Paulo, São Paulo, 2001.

SILVA, C. C. Caracterização dos comandos de produção textual da prova de redação do vestibular da UEM. Dissertação (Mestrado). Programa de Pós-Graduação em Letras da Universidade Estadual de Maringá. Maringá, 2018.

UENP - UNIVERSIDADE ESTADUAL DO NORTE DO PARANÁ. Vestibular UENP 2018, Caderno de Questões, Prova 1, Lingua Portuguesa, Literatura Brasileira, Língua Estrangeira Moderna - Espanhol - e Redação. 2018. Disponível em:

http://arquivo.vestibular.uenp.edu.br/vestibular/2018/site/docs/provas/prova_dia1_espanhol.p df. Acesso em: 15 abr. 2020.

ZANINI, M. Artigo de opinião: do ponto de vista à argumentação. In: ANTONIO, J. D.; NAVARRO, P. (org.). Gêneros textuais em contexto de vestibular. Maringá: Eduem, 2017. p. 43-57. 